\title{
A DATA-DRIVEN METHOD FOR VEHICLE SPEED ESTIMATION
}

Angelo Bonfitto, Stefano Feraco*

LIM - Laboratorio Interdisciplinare di Meccatronica, Dipartimento di Ingegneria Meccanica e Aerospaziale (DIMEAS), Politecnico di Torino, Torino, Italy

*E-mail of corresponding author: stefano.feraco@polito.it

\section{Resume}

This paper presents a method based on Artificial Neural Networks for estimation of the vehicle speed. The technique exploits the combination of two tasks: a) speed estimation by means of regression neural networks dedicated to different road conditions (dry, wet and icy); b) identification of the road condition with a pattern recognition neural network. The training of the networks is conducted with experimental datasets recorded during the driving sessions performed with a vehicle on different tracks. The effectiveness of the proposed approach is validated experimentally on the same car by deploying the algorithm on a dSPACE computing platform. The estimation accuracy is evaluated by comparing the obtained results to the measurement of an optical sensor installed on the vehicle and to the output of another estimation method, based on the mean value of velocity of the four wheels.

\section{Article info}

Received 15 October 2020

Accepted 25 November 2020

Online 7 April 2021

\section{Keywords:}

vehicle speed, artificial neural networks, estimation, regression, classification, road identification

\section{Introduction}

Automotive industry technologies witnessed a rapid evolution in the recent period, supported by the constant developments in the fields of electronics, actuation, automation and connectivity. Nowadays, commercial cars are highly performing and, at the same time, intelligent and sustainable [1]. Many benefits of the latest advancements are already tangible in terms of improved safety and comfort, reduction of the emissions and traffic congestions, lower stress for the car occupants and more confidence of the driver in a vehicle [2-3]. In this context, active strategies, relying on the real-time assessment of the vehicle dynamics assumes a crucial importance and the knowledge of the car states is a fundamental task, that is typically performed by direct measurement or, alternatively, by estimation and other indirect approaches [4]. However, some of the vehicle parameters (e.g. speed and sideslip angle) can be directly measured only with expensive, bulky and low robust devices, whose adoption in large production vehicles is not a viable solution. This motivates the considerable research effort that is recently being dedicated to investigation of alternative methods, such as the application of artificial intelligence to the assessment of vehicle dynamics [5-6]. In this paper, the attention is focused on estimation of the vehicle speed, a parameter that plays a key role in several active systems dedicated to control of the wheel slip, yaw rate and sideslip angle [7-8]. The direct measurement of the speed is commonly obtained using optical or GPS-based sensors [9]. However, these solutions may present some limitations according to the operating conditions. Optical sensors suffer problems of costs, size and sensitivity to dirt and environment conditions. On the other hand, the GPS-based sensors may be not sufficiently robust and reliable in specific atmospheric conditions as well as in situations with limited sky visibility, such as tunnels and urban environments with tall buildings. These problems can be partially overcome by analyzing signals coming from more satellites, using the Differential GPS technique or by exploiting two GPS antennas [10]. However, these approaches are still characterized by high signal latency time during the broadcasting of corrections. Typically, this latency is in the range of seconds, which might be far from the requirements of the active solutions implemented on board of a vehicle [11-12].

Alternative solutions are based on extraction of the speed information from vehicle analytical models [13]. A solution presented in [14] is based on e measurements of an Inertial Measurement Unit (IMU) using a slip detection estimator. This technique is typically implemented considering the unknown road condition as a bounded uncertainty and employing the estimated friction-independent tire forces for correcting the estimate. Nevertheless, the need for an accurate assessment of the road friction coefficient and of parameters related to the tires, which are highly time-varying, represents a relevant limitation of this 
technique. Further approaches exploit the Kalman Filter (KF) [15], Adaptive Kalman Filter (AKF) [16] and its nonlinear versions, Extended Kalman Filter (EKF) [17] and Unscented Kalman Filter (UKF) [18]. Other methods rely on similar filter/observer-based techniques [19-20]. However, these model-based techniques may suffer accuracy problems if the reference model is inaccurate or unable to reproduce the vehicle dynamics in all the driving conditions. An alternative class of techniques is based on Fuzzy Logic (FL) [21-24], which is strongly dependent on the designer experience and requires a highly refined definition of the rules and membership functions [25]. Finally, a common solution computes the speed as the average of the velocity of the four wheels. Although simple and cheap, this method may result as inaccurate when one or more wheels are locking during a sudden braking or start spinning and skidding, i.e. while driving on wet or icy roads and during the extreme manoeuvres.

This paper proposes a method to estimate the vehicle speed by using artificial intelligence to mitigate the limitations of model-based techniques and have an effective solution also in conditions that are difficult to represent in the models. Specifically, the presented method exploits a combination of regression and classification Artificial Neural Networks (ANNs). As well known, ANN-based approaches do not rely on any model and, if the networks are appropriately trained, may guarantee good levels of accuracy and robustness, as demonstrated by the growing attention that these methods are gaining in several engineering fields [2628]. To the author's knowledge, although the ANNs are widely documented as effective in executing system modeling and timeseries estimation, few research studies using the ANNs for the vehicle speed estimation are reported in the literature so far, since most of them rely on other techniques [29]. In this work, the proposed architecture includes two tasks: a) speed estimation computed by three parallel regression ANNs, dedicated to three different road conditions (dry, wet and icy road) and $b$ ) identification of the road condition with a pattern recognition neural classifier. The classifier output is used to select the correct estimation among the three outputs of the regression networks. Typically, the problem of the road condition detection is tackled with estimation of the friction coefficient with model-based approaches [30], regression ANNs [31-33], or exploiting the radar measurement [34-35]. In this study, on the contrary, the aim is not to provide the value of the friction coefficient, but the information of the class of the road condition: dry, wet or icy.

The ANNs' training datasets have been collected on a real vehicle, equipped with an optical sensor for acquisition of the reference speed, which is the target adopted during the supervised learning phase of the regression networks. Each regression network is trained with the dataset relative to the corresponding road condition. On the other hand, the input of the classifier is a single set of features extracted from the measured vehicle parameters and including all the road conditions. The validation of the method has been conducted experimentally on the same vehicle by deploying the designed algorithm on an auxiliary electronic control unit. The effectiveness of the approach is demonstrated by comparing the output of the estimator to the direct optical measurement and with another estimation computed as the average of the velocity of the four wheels. This estimation is extracted from an algorithm that was already deployed on the vehicle control unit.

The main contribution of this paper is the proposal of a data-driven method to estimate the vehicle speed. This approach has not been investigated yet in the literature and allows obtaining accurate results, if the training datasets effectively include all the significant behaviors of the vehicle in the widest possible set of handling manoeuvres and driving conditions. The good level of accuracy is quantified with the evidence obtained during the experimental validations. The results obtained on a high-performance vehicle allow highlighting the estimation behavior in extreme driving conditions.

The paper is structured as follows. The first section is dedicated to description of the vehicle setup and of the regression and classification tasks. Afterwards, the design of the neural networks for the speed estimation and for the road condition identification is illustrated. The last section presents the discussion of the experimental results obtained on the real vehicle in different driving conditions and in correspondence of road condition transients.

\section{Estimation method and vehicle setup}

The architecture of the proposed method is illustrated in Figure 1 and consists of two interconnected stages dedicated to the speed estimation and identification of the road condition. The former exploits three parallel Non-linear Autoregressive with Exogenous Input neural networks (NARX) and provides three outputs, one per each road condition: $\operatorname{dry}\left(\hat{v}_{x D}\right)$, wet $\left(\hat{v}_{x W}\right)$ and icy $\left(\hat{v}_{x I}\right)$.

The regression networks are fed with eight measurements listed in Table 1 (parameters 1 to 8 ) and trained with a supervised learning procedure using the speed measured by the optical sensor $\left(v_{x}\right)$ as the target output.

Inputs from 5 to 8 are computed as

$v_{i j}=\frac{1}{3.6} \cdot \frac{2 \pi}{60} \cdot\left(\omega_{i j} \cdot \rho_{i}\right)$,

where $i$ is $F$ or $R$, in the case of front or rear wheels, respectively, $j$ is $L$ or $R$, in the case of left or right wheels, respectively, $\omega_{i j}$ is the angular speed of the $i j$-wheel, expressed in round per minutes and $\rho_{i}$ is the wheel radius of the wheels, measured in meters. The total steering angle TS (input 4) is computed as the sum of the steering wheel angle (defined as the angle between 


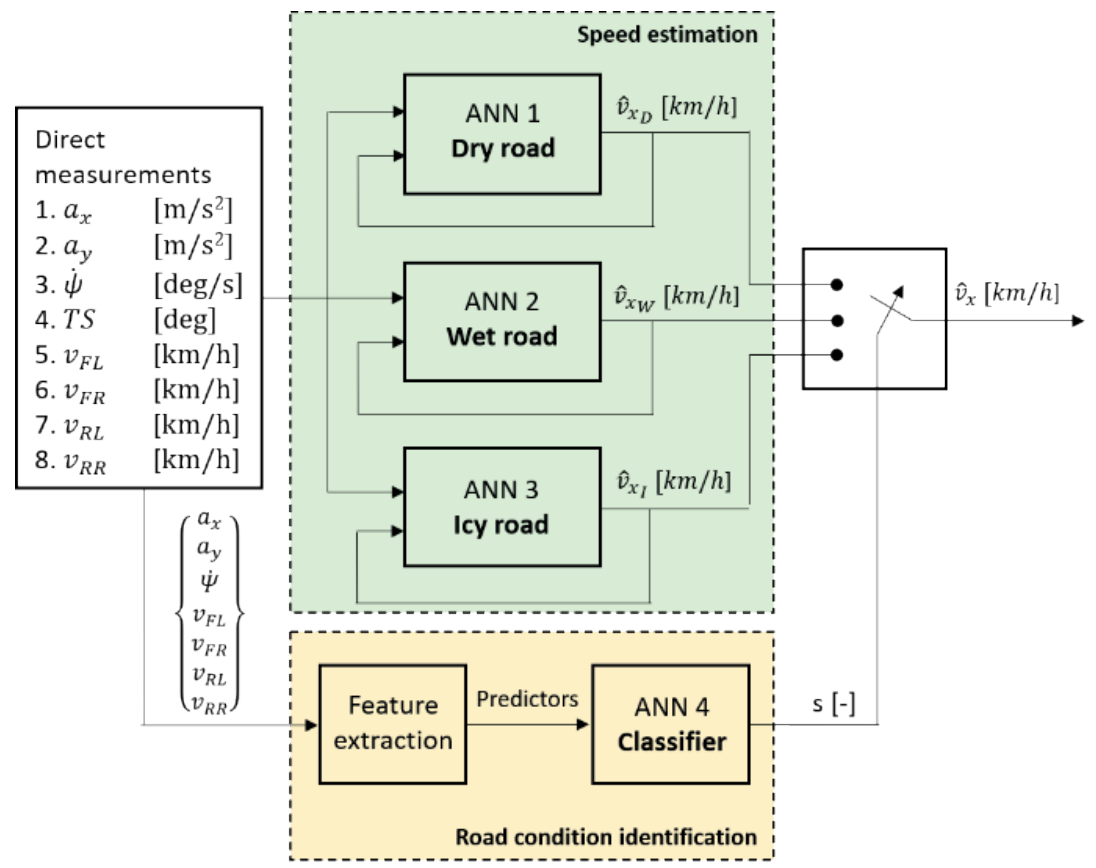

Figure 1 Layout of the estimation algorithm. Based on the actual road condition, the correct output is selected by a switch driven by the road condition identification classifier (output $S$ )

Table 1 Inputs of the estimation algorithm. R: parameters used for the three regression networks; C: parameters used for the classifier

\begin{tabular}{cccccc}
\hline$\#$ & type & task & parameters & name & unit \\
\hline 1 & input & R\&C & long. acceleration & $a_{x}$ & $\left(\mathrm{~m} / \mathrm{s}^{2}\right)$ \\
2 & input & R\&C & lat. acceleration & $a_{y}$ & $\left(\mathrm{~m} / \mathrm{s}^{2}\right)$ \\
3 & input & R\&C & yaw rate & $\dot{(d e g} / \mathrm{s})$ \\
4 & input & R & total steering angle & $T S$ & $(\mathrm{deg})$ \\
5 & input & R\&C & front left wheel speed & $v_{F L}$ & $(\mathrm{~km} / \mathrm{h})$ \\
6 & input & R\&C & front right wheel speed & $v_{F R}$ & $(\mathrm{~km} / \mathrm{h})$ \\
7 & input & R\&C & rear left wheel speed & $v_{R L}$ & $(\mathrm{~km} / \mathrm{h})$ \\
8 & input & R\&C & rear right wheel speed & $v_{R R}$ & $(\mathrm{~km} / \mathrm{h})$ \\
9 & target & R & vehicle speed & $v_{x}$ & $(\mathrm{~km} / \mathrm{h})$ \\
10 & target & C & class of the road & $D, W, I$ & $(-)$ \\
\hline
\end{tabular}

the vehicle's direction of motion and the steered wheel direction) and the active front steering input which is obtained from the electronic control unit of the vehicle.

The second stage allows identifying the road condition exploiting a classifier based on a pattern recognition feed-forward ANN. The classification process generates an output $(s)$ allowing to select the correct estimation among the outputs of the three regression networks above described.

The datasets adopted for the training of the regression and classification networks are collected on an instrumented vehicle in different test tracks and road conditions. The vehicle is a four-wheel drive (4WD) sport car with a power-to-weight ratio of around 0.35 $\mathrm{kW} / \mathrm{Kg}$ and a weight of about $1700 \mathrm{~kg}$. The vehicle is equipped with standard inertial sensors and a twoaxis optical sensor Correvit S-Motion from Kistler, which is exploited for the measurement of the speed and features a precision of $\pm 0.5 \mathrm{~km} / \mathrm{h}$, declared by the manufacturer. A dSPACE MicroAutoBox is interfaced with the CAN-bus of the vehicle to allow collecting the training datasets in the design phase and deploying the designed algorithm for the experimental validation. The sampling rate of the data acquisition is $100 \mathrm{~Hz}$.

The training dataset collection and experimental validation have been conducted in all the possible combinations of the different conditions that are reported in Table 2 .

The following driving conditions have been explored in three different adherence conditions (dry, wet and icy road): different tire-road friction coefficients; summer and winter tires; new and used tires; tests performed with and without the active safety system; tests performed by selecting different car driving modes; 
Table 2 Possibilities of driving conditions, vehicle setup and manoeuvres used for the training dataset collection and experimental validation. (ESC: Electronic Stability Control)

\begin{tabular}{cccc}
\hline road condition & maneuver & esc status & driving setup \\
dry & handling & ON & normal \\
wet & double lane change & OFF & racing \\
icy & sine-sweep & & \\
& sine steer & & \\
& step steer & \\
& acceleration/braking & \\
& steady-state cornering
\end{tabular}

Table 3 Training parameters of the three regression neural networks. The networks have a single hidden layer

\begin{tabular}{cccc}
\hline road condition & dry & wet & icy \\
\hline input buffer size $d_{x}$ & 2 & 3 & 2 \\
feedback buffer size $d_{y}$ & 2 & 3 & 2 \\
hidden layer size & 40 neurons & 60 neurons & 40 neurons \\
\hline training algorithm & & Levenberg-Marquardt backpropagation \\
\hline
\end{tabular}

tests performed with different driving styles and by professional and common drivers.

\section{Design of the estimator}

This section describes the design of the regression neural networks for the estimation of the speed and of the classifier for identification of the road condition.

\subsection{Regression task for the vehicle speed estimation}

A NARX ANN architecture is adopted for the regression task. This network allows modelling a discrete non-linear system. The output of the network is defined as:

$y(n)=\varphi\left[y(n-1), y(n-2), \ldots, y\left(n-d_{y}\right) ;\right.$

$\left.x(n-1), x(n-2), \ldots, x\left(n-d_{x}\right)\right]$,

where $x(n) \in \mathbb{R}$ and $y(n) \in \mathbb{R}$ are the inputs and outputs of the network at the discrete timestep $n$, respectively, $d_{x}$ and $d_{y}$ are the input and output buffer memory, respectively and $\varphi$ is the non-linear model represented by the network.

During the regression procedure, the value of the dependent output signal $y(n)$ is regressed on the previous $d_{y}$ values of the output signal considering previous $d_{x}$ values of the independent (exogenous) input signal. In the proposed solution, the NARX is adopted in open-loop during the training process and in closed-loop during the estimation phase, i.e. when the network is deployed on the electronic unit in the real application. The target input is $y^{*}(n)$, which is provided to the ANN during the supervised training phase. The Hidden Activation Function (HAF) is a hyperbolic tangent sigmoid and the
Output Activation Function (OAF) is a linear function. Table 3 reports the training parameters of the three networks, the number of neurons in the hidden layer and the input and feedback buffer size.

The networks are trained with the LevenbergMarquardt backpropagation algorithm. These characteristics are the result of a trial and error procedure, since the design and training of a neural network does not follow a standard procedure, as discussed in detail in [36] and [37].

\subsection{Classification task for the road condition identification}

The road condition identification is performed by the two-layered (one hidden and one output layer) feed forward pattern recognition ANN. This architecture connects an input feature space to an output space of multiple pattern classes and it has been already presented in the literature to solve classification problems in different engineering fields [38-39]. After a trial and error procedure, the hidden layer has been designed with a size of 50 neurons. The HAF is a hyperbolic tangent sigmoid and the OAF is a normalized exponential function. The adopted training procedure is based on the Levenberg-Marquardt backpropagation algorithm.

The input of the classifier is a set of 64 predictors, extracted from seven of the acquired signals, namely longitudinal and lateral accelerations $\left(a_{x}\right.$ and $a_{y}$ ), yaw rate $\dot{\phi}$ and longitudinal speed of the four wheels $\left(v_{F L}, v_{F R}, v_{R L}, v_{R R}\right)$ [6]. Features from 1 to 22 have a straightforward definition (mean, standard deviation, peak to RMS value and variance for the acquired signals). Features from 23 to 64 result from a spectral analysis performed on the input signals, where PSD stands for Power Spectral Density, computed using the 
Table 4 Summary of the conditions and estimation accuracy of the presented experimental cases. (ESC: Electronic Stability Control. MSE: mean square error of the proposed method, MSE ${ }_{A V G}$ : mean square error of the method based on the average of the four wheels' velocities)

\begin{tabular}{ccccccccccc}
\hline $\begin{array}{c}\text { validation } \\
\text { case }\end{array}$ & $\begin{array}{c}\text { road } \\
\text { condition }\end{array}$ & $\begin{array}{c}\text { driving } \\
\text { setup }\end{array}$ & esc & $\begin{array}{c}a_{x M A X} \\
\left(\mathrm{~m} / \mathrm{s}^{2}\right)\end{array}$ & $\begin{array}{c}a_{y M A X} \\
\left(\mathrm{~m} / \mathrm{s}^{2}\right)\end{array}$ & $\begin{array}{c}v_{x M A X} \\
(\mathrm{~km} / \mathrm{h})\end{array}$ & $\begin{array}{c}T S_{M A X} \\
(\mathrm{deg})\end{array}$ & $\begin{array}{c}\dot{\phi}_{\text {MAX }} \\
(\mathrm{deg} / \mathrm{s})\end{array}$ & $\begin{array}{c}M S E \\
(\mathrm{~km} / \mathrm{h})\end{array}$ & $\begin{array}{c}M S E_{A V G} \\
(\mathrm{~km} / \mathrm{h})\end{array}$ \\
\hline Figure 4 & dry & racing & OFF & 7.4 & 12.4 & 107.9 & 553.5 & 97.5 & 0.217 & 15.721 \\
Figure 5 & wet & sport & OFF & 6.7 & 10.1 & 172.2 & 153.1 & 40.1 & 0.003 & 4.172 \\
Figure 6 & icy & normal & ON & 3.5 & 4.1 & 88.7 & 201.3 & 32.8 & 0.763 & 26.142 \\
\hline
\end{tabular}

periodogram technique [40] by dividing the considered signal into multiple overlapping blocks and computing the average of their squared magnitude Fast Fourier Transforms (FFT) [41]. The average spectral power (features from 51 to 64) is computed as the integral of the PSD over the two adjacent frequency bands: $0.5 \div 1.5 \mathrm{~Hz}$ (frequency band 1 ) and $1.5 \div 5 \mathrm{~Hz}$ (frequency band 2). The predictors are collected in buffers with a time length of $2 \mathrm{~s}$ and refilled with a frequency of 10 $\mathrm{Hz}$, which is the output rate of the classifier and hence of the overall estimation output $\hat{v}_{x}$.

The set of predictors was selected by a trial and error procedure, performed to maximize the accuracy of the classification task. A more refined selection phase could be performed after a quantification of the influence of each predictor. This aspect is currently a hot research topic [42-43], nevertheless, this analysis is beyond the scope of the present study and would require a dedicated work.

\section{Results and discussion}

The results are presented in different driving and road conditions. This section is dedicated to the analysis of the estimation behavior in correspondence of road condition transients.

\subsection{Speed estimation}

The accuracy of the proposed method is evaluated by comparing the estimation $\left(\hat{v}_{x}\right)$ to the measurement of the optical sensor mounted onboard the vehicle $\left(v_{x}\right)$ and with a further estimation computed as the average of the velocity of the four wheels $\left(\hat{v}_{x A V G}\right)$. The latter is an algorithm that was already deployed in the electronic control unit of the vehicle.

The more relevant experimental results are reported in the following figures. The graphs illustrate the comparison between $v_{x}, \hat{v}_{x}$ and $\hat{v}_{x A V G}$ in the subplot $a$, the absolute error of the two estimation methods with respect to the measured value in the subplot $b$ ( $\left.\varepsilon_{1}=\hat{v}_{x}-v_{x}, \varepsilon_{2}=\hat{v}_{x A V G}-v_{x}.\right)$ and behavior of the ANN input signals, specifically the longitudinal $a_{x}$ and lateral $a_{y}$ accelerations (subplot $c$ ), the total steering angle (subplot $d$ ), the wheels' speed (subplot $e$ ) and the yaw rate (subplot $f$ ). The main characteristics of the validation cases are summarized in Table 4 , where $M S E$ and $M S E_{A V G}$ are the mean square error of the proposed method and of the method based on the average of the four wheels' velocity, respectively.

They are computed as follows:

$$
\begin{aligned}
& M S E=\frac{1}{n} \sum_{i=1}^{n}\left(v_{x}(i)-\hat{v}_{x}(i)\right)^{2}, \\
& M S E_{A V G}=\frac{1}{n} \sum_{i=1}^{n}\left(v_{x}(i)-\hat{v}_{x A V G}(i)\right)^{2} .
\end{aligned}
$$

Figure 2 shows results obtained on a dry asphalt with the Electronic Stability Control (ESC) system off and the car set in the racing driving mode. At $20 \mathrm{~s}$, a sine-sweep manoeuvre is performed with a frequency of TS increasing from $0.5 \mathrm{~Hz}$ to $1.5 \mathrm{~Hz}$ and the speed $v_{x}$ equal to around $50 \mathrm{~km} / \mathrm{h}$. Three additional sine-sweep manoeuvres are performed at 40,60 and $90 \mathrm{~s}$ and a stepsteer manoeuvre is performed at $130 \mathrm{~s}$, when the vehicle longitudinal speed goes to zero, while TS reaches -550 deg.

The speed is estimated accurately by the ANNbased algorithm. On the other hand, $\hat{v}_{x A V G}$ is affected by a relevant error at $155 \mathrm{~s}$ during a sudden braking, whereas the estimation of the proposed ANN-based method remains accurate. The error $\varepsilon_{2}$ (dashed line) presents high peaks confirming that the estimate provided by the wheels' velocity average may be not completely reliable during some extreme manoeuvres.

Figure 3 represents results obtained on a wet asphalt with the ESC system switched off and the car set in sport driving mode, during a lap on a handling circuit. During this acquisition, the driver has performed successive demanding manoeuvres, reaching $160 \mathrm{~km} / \mathrm{h}$ and steering from $-150 \mathrm{deg}$ to $150 \mathrm{deg}$. The speed is estimated accurately by the proposed method, whereas the error $\varepsilon_{2}$ reaches peaks of $7 \mathrm{~km} / \mathrm{h}$.

Figure 4 shows results obtained on an icy asphalt with the ESC system enabled and the car set in normal driving mode. At the beginning of this acquisition, the driver performed a sine-sweep manoeuvre at an almost constant speed equal to about $40 \mathrm{~km} / \mathrm{h}$, while steering from $-80 \mathrm{deg}$ to $100 \mathrm{deg}$ for about $30 \mathrm{~s}$. The frequency of $T S$ increases from $0.5 \mathrm{~Hz}$ to about $2 \mathrm{~Hz}$ during the sinesweep manoeuvre. Afterwards, the driver performed a step-steer manoeuvre with TS equal to $-200 \mathrm{deg}$, once the vehicle has reached a maximum speed equal to about $90 \mathrm{~km} / \mathrm{h}$. The speed is estimated accurately by the ANNbased investigated method. 
On the contrary, the estimation $\hat{v}_{x A V G}$ is not accurate during the last manoeuvre, since the four wheels start skidding and blocking on the icy road surface, as represented in Figure 4.d. The absolute error $\varepsilon_{2}$ reaches $70 \mathrm{~km} / \mathrm{h}$ in Figure $4 . \mathrm{b}$ during the last manoeuvre, while the error $\varepsilon_{1}$ is limited to less than $5 \mathrm{~km} / \mathrm{h}$ in correspondence of demanding manoeuvres.
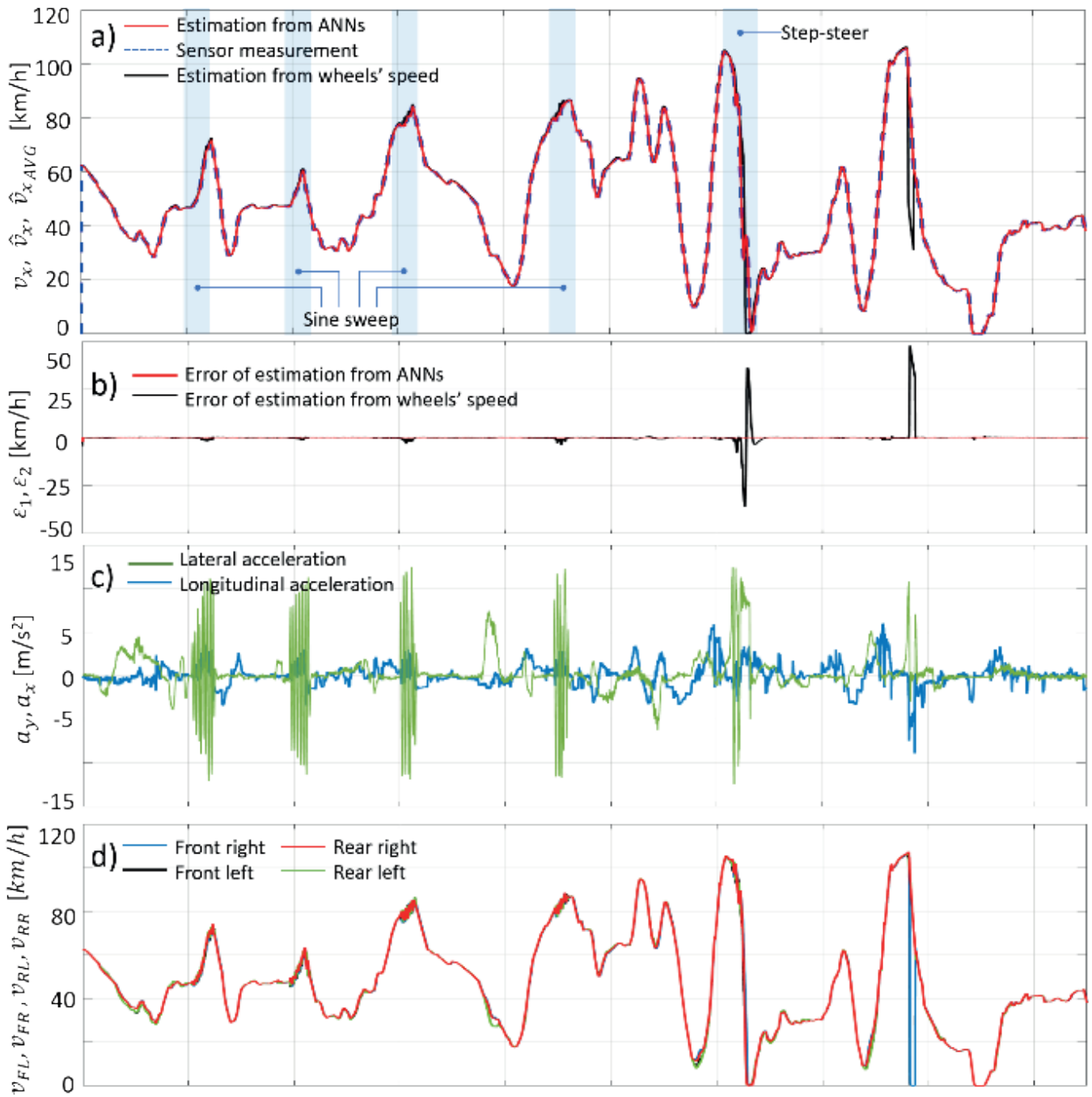

600
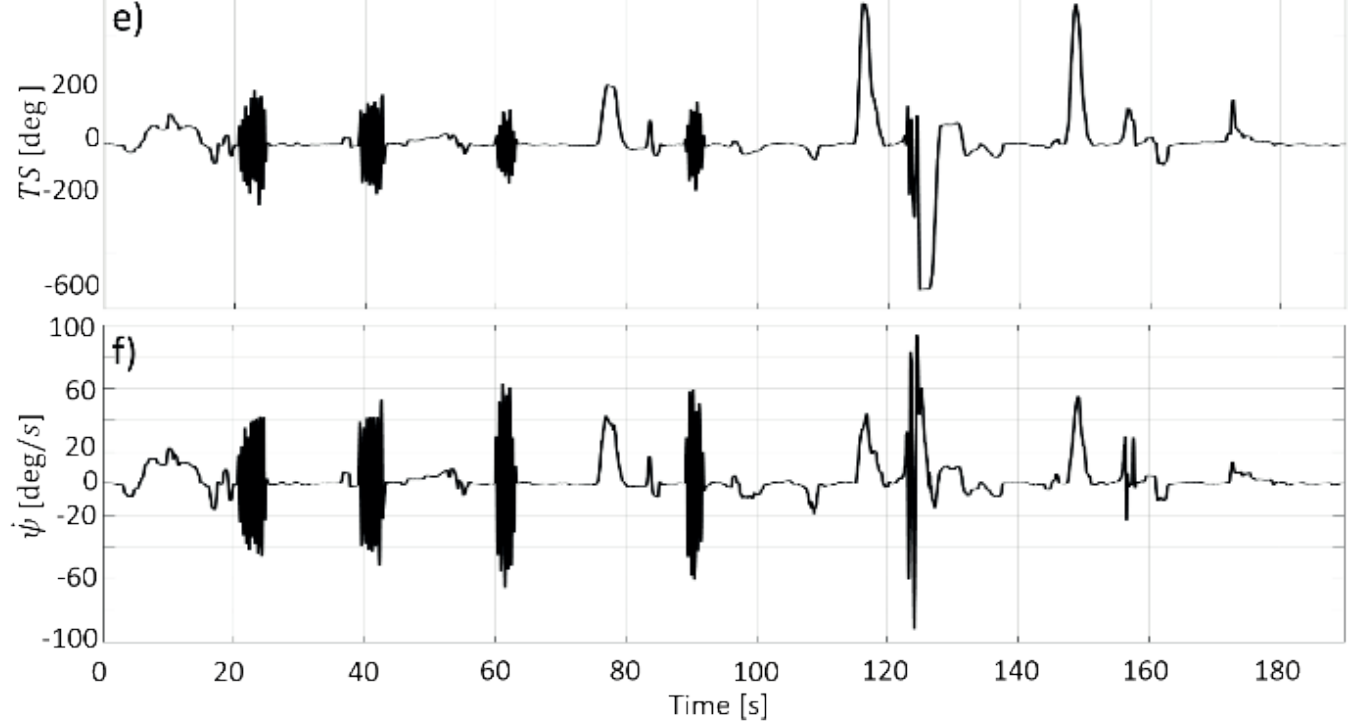

Figure 2 Test 1. Dry road. a) Vehicle speed b) Absolute estimation errors. c) Longitudinal and lateral acceleration. d) Wheels' longitudinal speed. e) Total steering angle. f) Yaw rate. The commanded manoeuvres are highlighted in light blue areas 


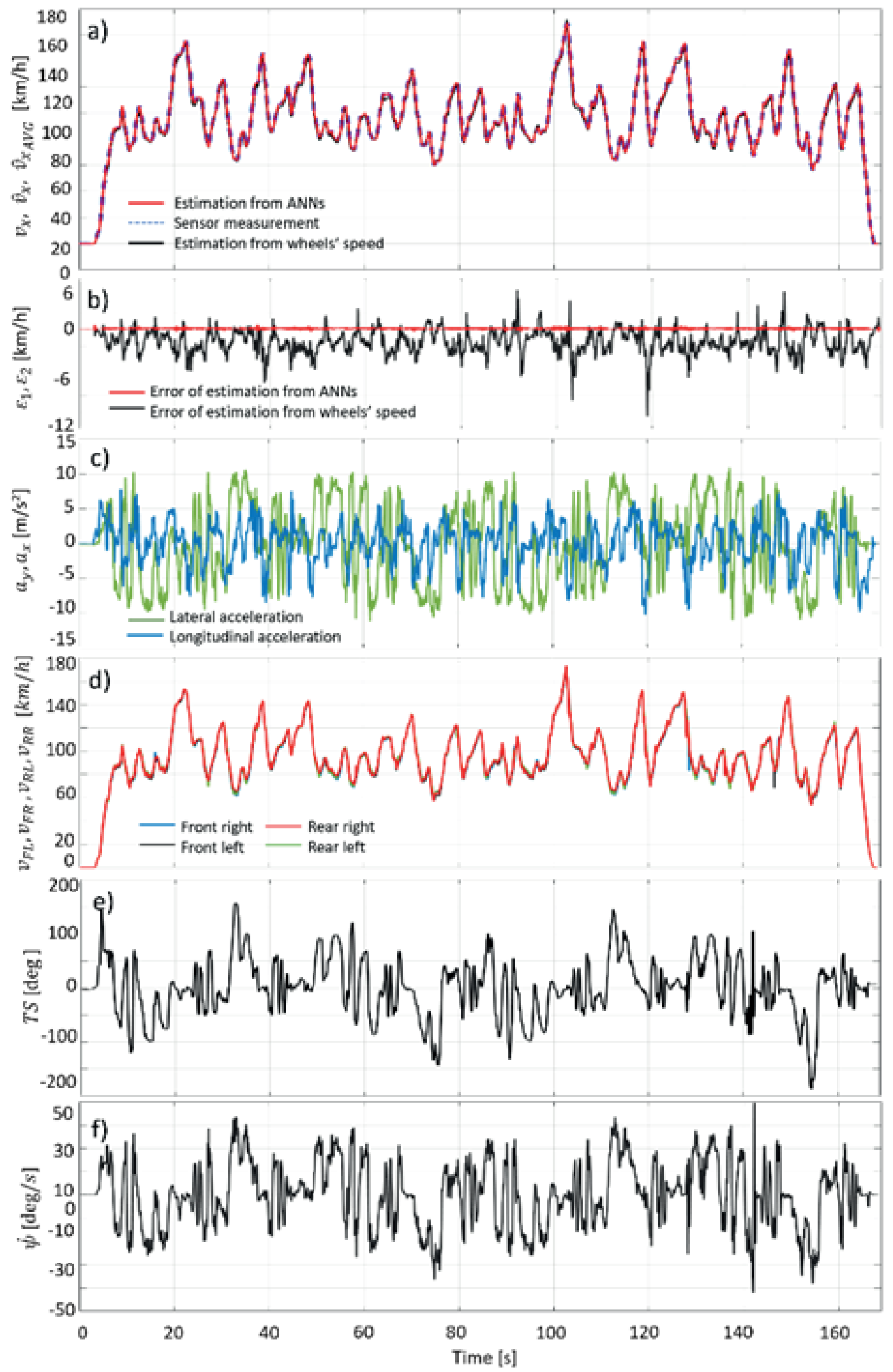

Figure 3 Test 1. Wet road. a) Vehicle speed b) Absolute estimation errors. c) Longitudinal and lateral acceleration. d) Wheels longitudinal speed. e) Total steering angle. f) Yaw rate 

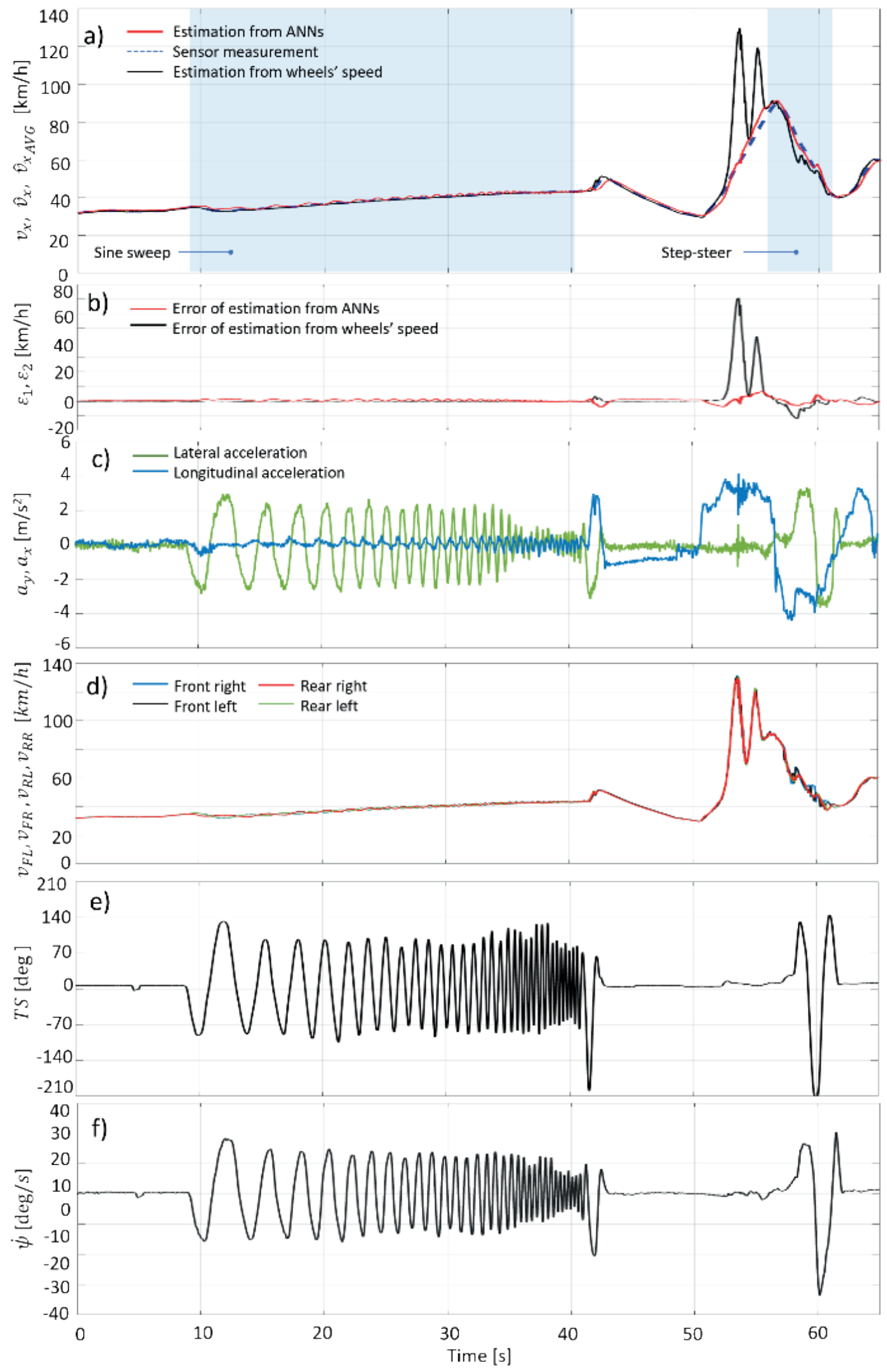

Figure 4 Test 1. Icy road. a) Vehicle speed b) Absolute estimation errors. c) Longitudinal and lateral acceleration. d) Wheels longitudinal speed. e) Total steering angle. f) Yaw rate. The commanded manoeuvres are highlighted in light blue areas 


\begin{tabular}{|c|c|c|c|c|}
\hline & & al road cond & & \\
\hline & Dry & Wet & Icy & \\
\hline 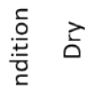 & $\begin{array}{c}37805 \\
\mathrm{CL}: 35.35 \%\end{array}$ & $\begin{array}{c}151 \\
\text { CL: } 0.14 \%\end{array}$ & $\begin{array}{c}120 \\
C L: 0.11 \%\end{array}$ & \\
\hline 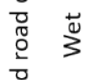 & $\begin{array}{c}114 \\
C L: 0.11 \%\end{array}$ & $\begin{array}{c}25085 \\
\text { CL: } 23.46 \%\end{array}$ & $\begin{array}{c}32 \\
\mathrm{CL}: 0.03 \%\end{array}$ & \\
\hline 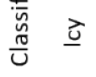 & $\begin{array}{c}104 \\
\mathrm{CL}: 0.1 \%\end{array}$ & $\begin{array}{c}10 \\
C L: 0.01 \%\end{array}$ & $\begin{array}{c}43523 \\
\text { CL: } 40.7 \%\end{array}$ & \\
\hline & $\begin{array}{c}N_{D}: \\
38023 \\
\alpha_{C_{D}} \\
99.43 \%\end{array}$ & $\begin{array}{c}N_{W}: \\
25246 \\
\alpha_{C_{W}} \\
99.36 \%\end{array}$ & $\begin{array}{c}N_{I}: \\
43675 \\
\alpha_{C_{I}} \\
99.65 \%\end{array}$ & $\begin{array}{c}N_{T O T}: \\
106944 \\
\alpha_{C_{T O T}} \\
99.5 \%\end{array}$ \\
\hline
\end{tabular}

Figure 5 Confusion matrix of the classifier for the road condition identification

\subsection{Road condition identification}

The performance of the road condition identification is evaluated with a Confusion Matrix $(C M)$ reported in Figure 5. The classified and actual road conditions instances are reported in the rows and columns, respectively. The values contained in the main diagonal cells indicate the correct classifications, whereas the offdiagonal cells report the number of the misclassifications. The data provided as input to the classifier are buffers with a duration of 2 seconds containing the features extracted in the classification process. These buffered data are overlapped with a time-shift of $0.1 \mathrm{~s}$, thus the total number of input buffers $\left(N_{T O T}\right)$ is 106944 , equal to the sum of 38023 in dry $\left(N_{D}\right), 25246$ in wet $\left(N_{W}\right)$ and 43675 in icy $\left(N_{I}\right)$ acquisitions, corresponding to a total acquisition time of $10694.4 \mathrm{~s}$.

For each cell, a classification rate $C L$ is computed as the ratio between the number of cell instances $N_{i, j}$ and the total number of instances $N_{\text {тот: }}$ :

$$
C L_{i, j}=\frac{N_{i, j}}{N_{T O T}} .
$$

The classification accuracy for each road condition is computed as follows:

$\alpha_{C D}=\frac{N_{1,1}}{N_{D}}, \alpha_{C W}=\frac{N_{2,2}}{N_{W}}, \alpha_{C I}=\frac{N_{3,3}}{N_{I}}$,

for dry, wet and icy asphalt, respectively. The total classification accuracy is equal to $99.5 \%$, computed as

$\alpha_{\text {СтоT }}=\frac{N_{1,1}+N_{2,2}+N_{3,3}}{N_{T O T}}$.

\subsection{Validation during the road condition transients}

Accuracy of the road conditions identification has been validated also in correspondence of the transient between the two different conditions: a) from dry to wet and from wet to dry and b) from wet to icy and from icy to wet.

Figure 6 reports the acquisition recorded with the car in normal driving mode and the ESC system disabled. During the initial part of the acquisition, the road is dry. Then, the road condition becomes wet at about $40 \mathrm{~s}$. At around $80 \mathrm{~s}$, the road is dry again. The output of the classifier $S$ is reported in Figure 6 where the zoomed regions report the buffers along with the classification outputs. The second zoomed area is reported because it represents the occurrence of a misclassification. In this case, $S$ indicates a wet road condition, although the asphalt is dry. However, this misclassification does not affect the longitudinal speed estimation, as represented in Figure 6.

In Figure 7, the results obtained during the road condition transient from wet to icy and from icy to wet are represented. The car has the ESC system enabled and is set in racing driving mode. The classification output $S$ is reported in the zoomed portions. All the buffers are correctly classified and the final value of the estimation is accurate, as represented in Figure 7.

The number of misclassifications in correspondence of the road conditions change is very limited. This result has been achieved by reducing the length of the buffers considered for the feature extraction in the classification task. As a matter of fact, the larger the buffer, the higher is the possibility to incur in misclassifications. The high rate of classification output is also advantageous to limit the effect of estimation inaccuracies due to misclassifications. The estimation error is indeed recovered within the period of $0.1 \mathrm{~s}$, corresponding to the output rate of the classifier. This motivates the absence of major estimation inaccuracies in correspondence of the misclassifications.

\section{Conclusions}

In this paper, a data-driven method for the vehicle speed estimation has been presented. The proposed technique exploits a combination of regression and 


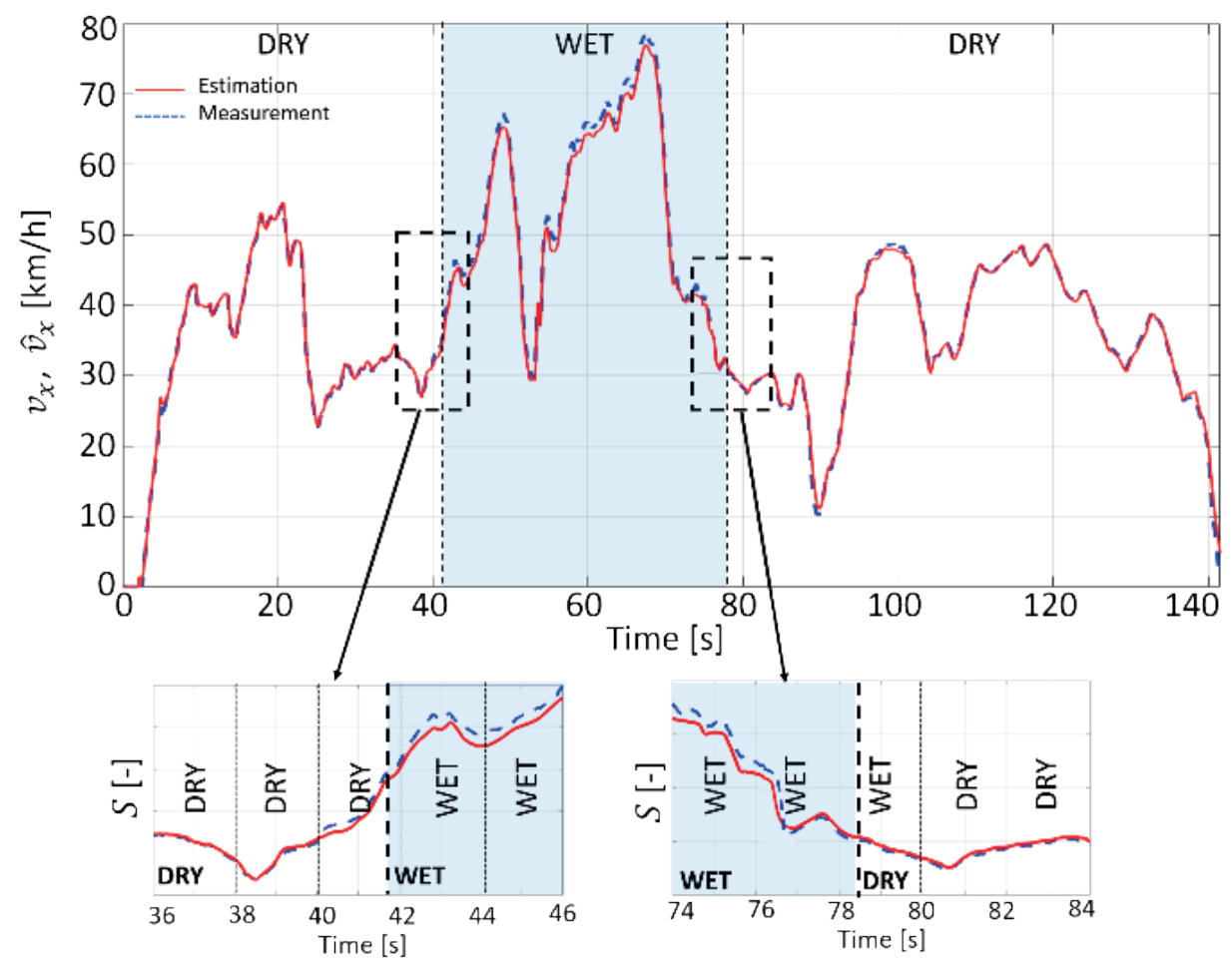

Figure 6 Test performed in transient road conditions (dry-wet-dry). a) measured $v_{x}$ (dashed) vs. estimated by the ANN-based algorithm $\hat{v}_{x}$ (solid) longitudinal speed. In the zoomed regions: ANN-based classifier's output $S$

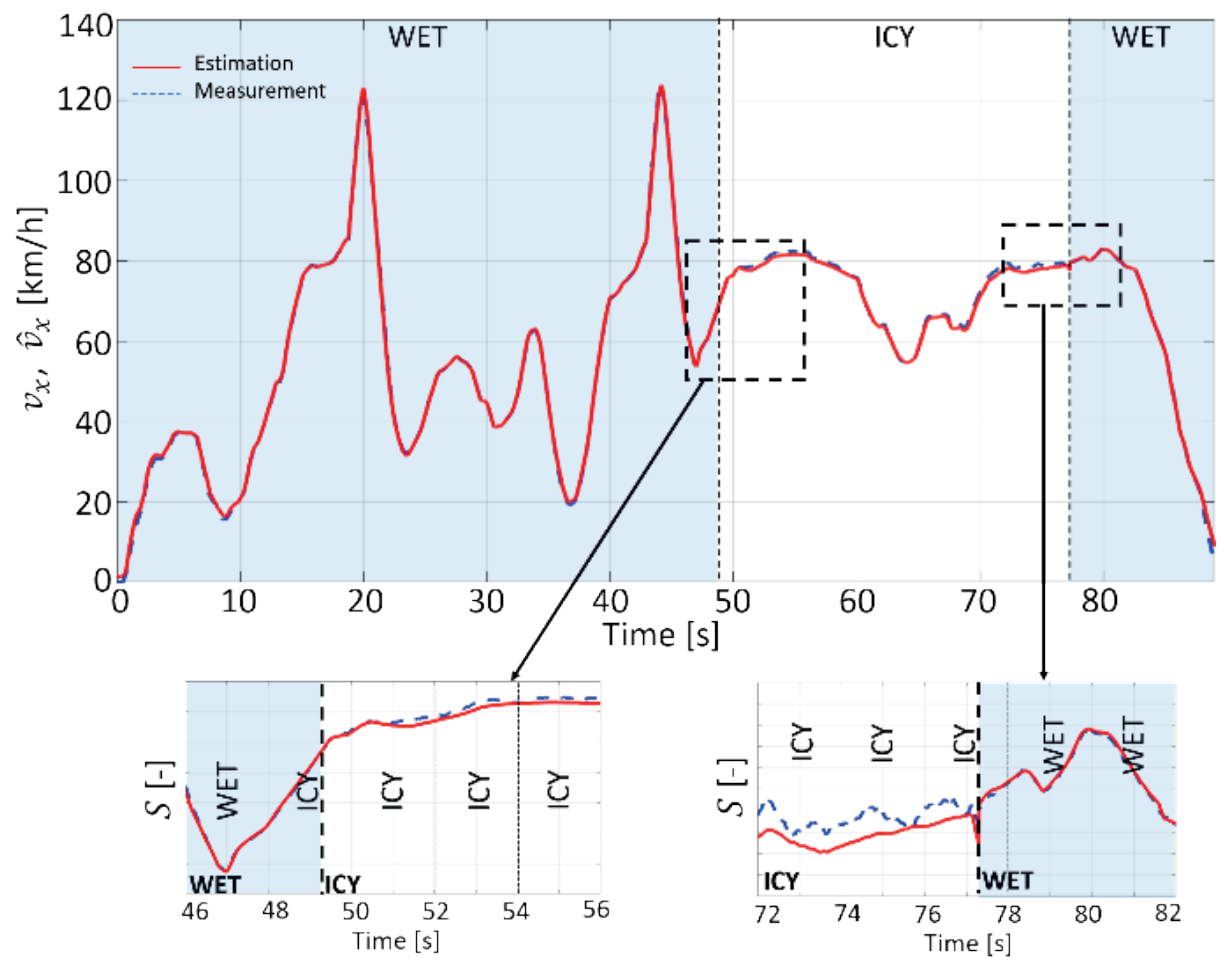

Figure 7 Test performed in transient road conditions (wet-dry-wet). a) measured $v_{x}$ (dashed) vs. estimated by the ANN-based algorithm $\hat{v}_{x}$ (solid) longitudinal speed. In the zoomed regions: ANN-based classifier's output $S$

classification neural networks task to estimate the speed and identify the road condition. The solution is presented as a reliable alternative to existing methods to mitigate the limitations due to the model 
representation. The performance of the method was evaluated experimentally in several driving conditions. The good match between the estimated and measured values of speed demonstrates the effectiveness of the method, also in correspondence of transients between different road conditions.

\section{Acknowledgement}

This work was developed in the framework of activities of the Interdepartmental Center for Automotive Research and Sustainable Mobility (CARS) of Politecnico di Torino (www.cars.polito.it).

\section{References}

[1] OKUDA, R., KAJIWARA, Y., TERASHIMA, K. A survey of technical trend of ADAS and autonomous driving. In: VLSI Technology, Systems and Application VLSI-TSA: proceedings [online]. IEEE. 2014. ISBN 978-1-4799-27760. Available from: https://doi.org/10.1109/VLSI-DAT.2014.6834940

[2] SHIBAHATA, Y., SHIMADA, K., TOMARI, T. Improvement of vehicle manoeuvreability by direct yaw moment control. Vehicle System Dynamics [online]. 1993, 22(5-6), p. 465-481. ISSN 0042-3114, eISSN 1744-5159. Available from: https://doi.org/10.1080/00423119308969044

[3] LUCIANI, S., BONFITTO, A., AMATI, N., TONOLI, A. Model predictive control for comfort optimization in assisted and driverless vehicles. Advances in Mechanical Engineering [online]. 2020, 12(11). ISSN 1687-8140, eISSN 1687-8140. Available from: https://doi.org/10.1177/1687814020974532

[4] FODOR, M., YESTER, J., HROVAT, D. Active control of vehicle dynamics. In: 17th Digital Avionics Systems Conference DASC: proceedings [online]. The AIAA/IEEE/SAE. Vol. 2. 1998. ISBN 0-7803-5086-3, p. I14/1-I14/8. Available from: https://doi.org/10.1109/DASC.1998.739865

[5] YIM, Y. U., OH, S. Y. Modeling of vehicle dynamics from real vehicle measurements using a neural network with two-stage hybrid learning for accurate long-term prediction. IEEE Transactions on Vehicular Technology [online]. 2004, 53(4), p. 1076-1084. ISSN 0018-9545. Available from: https://doi.org/10.1109/TVT.2004.830145

[6] BONFITTO, A., FERACO, S., TONOLI, A., AMATI, N. Combined regression and classification artificial neural networks for sideslip angle estimation and road condition identification. Vehicle System Dynamics [online]. 2019, 58(11), p. 1766-1787. ISSN 0042-3114, eISSN 1744-5159. Available from: https://doi.org/10.1080/00423114.2019.16 45860

[7] CIROVIC, V., ALEKSENDRIC, D., SMILJANIC, D. Longitudinal wheel slip control using dynamic neural networks. Mechatronics [online]. 2013, 23(1), p. 135-146. ISSN 0957-4158. Available from: https://doi.org/10.1016/j. mechatronics.2012.11.007

[8] MANNING, W. J., CROLLA, D. A. A review of yaw rate and sideslip controllers for passenger vehicles. Transactions of the Institute of Measurement and Control [online]. 2007, 29(2), p. 117-135. ISSN 0142-3312, eISSN 1477-0369. Available from: https://doi.org/10.1177/0142331207072989

[9] BEVLY, D. M., GERDES, J. C., WILSON, C., ZHANG, G. The use of GPS based velocity measurements for improved vehicle state estimation. In: 2000 American Control Conference ACC: proceedings [online]. IEEE. 2000. ISSN 0743-1619, ISBN -7803-5519-9. Available from: https://doi.org/10.1109/ACC.2000.878665

[10] JANG, J., SUNG, S., LEE, Y. J. Improvement of differential GPS performance using range measurements between satellites. International Journal of Aeronautical and Space Sciences [online]. 2020, 21(1), p. 201-209. ISSN 2093-274X, eISSN 2093-2480. Available from: https://doi.org/10.1007/s42405-019-00198-x

[11] SOLOMON, P. D., WANG, J., RIZOS, C. Latency determination and compensation in real-time GNSS/INS integrated navigation systems. International Archives of the Photogrammetry, Remote Sensing and Spatial Information Sciences 2011 ISPRS Workshop: proceedings [online]. Vol. XXXVIII-1/C22. 2011. p. 303-307. Available from: https://doi.org/10.5194/isprsarchives-XXXVIII-1-C22-303-2011

[12] WANG, Z., HAMEDI, M. YOUNG, S. Methodology for calculating latency of GPS probe data. Transportation Research Record: Journal of the Transportation Research Board [online]. 2017, 2645(1), p. 76-85. ISSN 0361-1981, eISSN 2169-4052. Available from: https://doi.org/10.3141/2645-09

[13] KO, S. Y., KO, J. W., LEE, S. M., CHEON, J. S., KIM, H. S. Vehicle velocity estimation using effective inertia for an in-wheel electric vehicle. International Journal of Automotive Technology [online]. 2014, 15(5), p. 815-821. ISSN 1229-9138, eISSN 1976-3832. Available from: https://doi.org/10.1007/s12239-014-0085-8

[14] HASHEMI, E., KHOSRAVANI, S., KHAJEPOUR, A., KASAIEZADEH, A., CHEN, S. K., LITKOUHI, B. Longitudinal vehicle state estimation using nonlinear and parameter-varying observers. Mechatronics [online]. 2017, 43, p. 28-39. ISSN 0957-4158. Available from: https://doi.org/10.1016/j.mechatronics.2017.02.004

[15] KLOMP, M., GAO, Y., BRUZELIUS, F. Longitudinal velocity and road slope estimation in hybrid electric vehicles employing early detection of excessive wheel slip. Vehicle System Dynamics [online]. 2014, 52(sup1), p. 172-188. ISSN 0042-3114, eISSN 1744-5159. Available from: https://doi.org/10.1080/00423114.2014.887737 
[16] CHU, L., SHI, Y., ZHANG, Y., LIU, H., XU, M. Vehicle lateral and longitudinal velocity estimation based on adaptive Kalman filter. In: 3rd International Conference on Advanced Computer Theory and Engineering ICACTE: proceedings [online]. IEEE. 2010. Available from: https://doi.org/10.1109/ICACTE.2010.5579565

[17] CHU, L., XHANG, Y., SHI, Y., XU, M., OU, Y. Vehicle lateral and longitudinal velocity estimation using coupled EKF and RLS methods. Applied Mechanic and Materials [online]. 2010, 29-32, p. 851-856. ISSN 1662-7482. Available from: https://doi.org/10.4028/www.scientific.net/AMM.29-32.851

[18] CHU, L., ZHANG, Y., SHI, Y., XU, M., LIU, M. Vehicle lateral and longitudinal velocity estimation based on unscented Kalman filter. In: 2nd International Conference on Education Technology and Computer: proceedings [online]. IEEE. 2010. ISSN 2155-1812. Available from: https://doi.org/10.1109/ICETC.2010.5529507

[19] MOAVENI, B., ABAD, M. K. R., NASIRI, S. Vehicle longitudinal velocity estimation during the braking process using unknown input Kalman filter. Vehicle System Dynamics [online]. 2015, 53(10), p. 1373-1392. ISSN 0042-3114, eISSN 1744-5159. Available from: https://doi.org/10.1080/00423114.2015.1038279

[20] ZHAO, L., LIU, Z., CHEN, H. Design of a nonlinear observer for vehicle velocity estimation and experiments. IEEE Transactions on Control Systems Technology [online]. 2011, 19(3), p. 664-672. ISSN 1063-6536, eISSN 1558-0865. Available from: https://doi.org/10.1109/TCST.2010.2043104

[21] GAO, X., YU, Z., XU, T. Longitudinal velocity estimation of electric vehicle with 4 in-wheel motors. In: SAE World Congress and Exhibition Vehicle Dynamics and Simulation: proceedings [online]. USA: SAE International. 2008. ISSN 0148-7191, eISSN 2688-3627, 2008-01-0605. Available from: https://doi.org/10.4271/2008-01-0605

[22] JIN, C., SHAO, L., LEX, C., EICHBERGER, A. Vehicle side slip angle observation with road friction adaptation. IFAC PapersOnLine [online]. 2017, 50(1), p. 3406-3411. ISSN 2405-8963. Available from: https://doi.org/10.1016/j. ifacol.2017.08.593

[23] BASSET, M., ZIMMER, C., GISSINGER, G. L. Fuzzy approach to the real time longitudinal velocity estimation of a FWD car in critical situations. Vehicle System Dynamics [online]. 1997, 27, p. 477-489. ISSN 0042-3114, eISSN 1744-5159. Available from: https://doi.org/10.1080/00423119708969343

[24] JIN, L., CHEN, P., ZHANG, R. AND LING, M. Longitudinal velocity estimation based on fuzzy logic for electronic stability control system. Advances in Mechanical Engineering [online]. 2017, 9(5), p. 1-12. ISSN 1687-8140, eISSN 1687-8140. Available from: https://doi.org/10.1177/1687814017698662

[25] BONFITTO, A., FERACO, S., ROSSINI, M., CARLOMAGNO, F. Fuzzy logic method for the speed estimation in all-wheel drive electric racing vehicles. Communications-Scientific Letters of the University of Zilina [online]. 2021, 23(2), p. B117-B129. ISSN 1335-4205, eISSN 2585-7878. Available from: https://doi.org/10.26552/ com.C.2021.2.B117-B129

[26] BONFITTO, A., FERACO, S., AMATI, N., TONOLI, A. Virtual sensing in high-performance vehicles with artificial intelligence. In: International Design Engineering Technical Conferences and Computers and Information in Engineering Conference IDETC - CIE 2019: proceedings. Vol. 59216. American Society of Mechanical Engineers, 2019. p. V003T01A005.

[27] BONFITTO, A., FERACO, S., TONOLI, A., AMATI, N., MONTI, F. Estimation accuracy and computational cost analysis of artificial neural networks for state of charge estimation in lithium batteries. Batteries [online]. 2019, 5(2), 47. eISSN 2313-0105. Available from: https://doi.org/10.3390/batteries5020047

[28] PROKHOROV, D. Neural networks in automotive applications. In: Computational intelligence in automotive applications. PROKHOROV, D. (ed.). Berlin, Heidelberg: Springer, 2008. ISBN 978-3-540-79257-4, p. 101-123.

[29] MARKEVICIUS, V., NAVIKAS, D., IDZKOWSKI, A., ANDRIUKAITIS, D., VALINEVICIUS, A., ZILYS, M. Practical methods for vehicle speed estimation using a microprocessor-embedded system with AMR sensors. Sensors [online]. 2018, 18, 2225. eISSN 1424-8220. Available from: https://doi.org/10.3390/s18072225

[30] WANG, B., GUAN, H., LU, P., ZHANG, A. Road surface condition identification approach based on road characteristic value. Journal of Terramechanics [online]. 2014, 56, p. 103-117. ISSN 0022-4898. Available from: https://doi.org/10.1016/j.jterra.2014.09.001

[31] LIU, C. S., HUEI, P. Road friction coefficient estimation for vehicle path prediction. Vehicle System Dynamics [online]. 1996, 25(sup1), p. 413-425. ISSN 0042-3114, eISSN 1744-5159. Available from: https://doi.org/10.1080/00423119608969210

[32] AGUILAR, J. J. C., CARRILLO, J. A. C., FERNANDEZ, A. J. G., ACOSTA, E. C. Robust road condition detection system using in-vehicle standard sensors. Sensors [online]. 2015, 15(12), p. 32056-32078. eISSN 1424-8220. Available from: https://doi.org/10.3390/s151229908

[33] NGWANGWA, H. M., HEYNS, P. S. Application of an ANN-based methodology for road surface condition identification on mining vehicles and roads. Journal of Terramechanics [online]. 2014, 53, p. 59-74. ISSN 0022-4898. Available from: https://doi.org/10.1016/j.jterra.2014.03.006

[34] VIIKARI, V. V., VARPULA, T., KANTANEN, M. Road condition recognition using 24-GHz automotive radar. IEEE Transactions on Intelligent Transportation Systems [online]. 2009, 10, p. 639-648. ISSN 1558-0016. Available from: https://doi.org/10.1109/TITS.2009.2026307 
[35] ASUZU, P., THOMPSON, C. Road condition identification from millimeter-wave radar backscatter measurements. IEEE Radar Conference RadarConf18: proceedings [online]. IEEE. 2018. ISSN 2375-5318. Available from: https://doi.org/10.1109/RADAR.2018.8378522

[36] SHEELA, K. G., DEEPA, S. N. Review on methods to fix number of hidden neurons in neural networks. Mathematical Problems in Engineering [online]. 2013, 2013, 425740. ISSN 1024-123X, eISSN 1563-5147. Available from: https://doi.org/10.1155/2013/425740

[37] GOODFELlOW, I., BENGIO Y., COURVILlE, A. Deep learning. Boston, USA: The MIT press, 2016. ISBN 978-0262035613.

[38] OU, G., MURPHEY, Y. L. Multi-class pattern classification using neural networks. Pattern Recognition [online]. 2007, 40(1), p. 4-18. ISSN 0031-3203. Available from: https://doi.org/10.1016/j.patcog.2006.04.041

[39] BONFITTO, A., TONOLI, A., FERACO, S., ZENERINO, E. C., GALLUZZI, R. Pattern recognition neural classifier for fall detection in rock climbing. Proceedings of the Institution of Mechanical Engineers Part P Journal of Sports Engineering and Technology [online]. 2019, 233(4), p. 478-488. ISSN 1754-3371, eISSN 1754-338X. Available from: https://doi.org/10.1177/1754337119850927

[40] WELCH, P. The use of Fast Fourier Transform for the estimation of power spectra: a method based on time averaging over short, modified periodograms. IEEE Transactions on Audio and Electroacoustics [online]. 1967, 15(2), p. 70-73. ISSN 0018-9278, eISSN 1558-2582. Available from: https://doi.org/10.1109/TAU.1967.1161901

[41] RENAUDIN, V., SUSI, M., LACHAPELLE, G. Step length estimation using handheld inertial sensors. Sensors [online]. 2012, 12, p. 8507-8525. eISSN 1424-8220. Available from: https://doi.org/10.3390/s120708507

[42] MANORANJAN, D., HUAN, L. Feature selection for classification. Intelligent Data Analysis [online]. 1997, 1(1-4), p. 131-156. ISSN 1088-467X. Available from: https://doi.org/10.1016/S1088-467X(97)00008-5

[43] JANECEK, A., GANSTERER, W., DEMEL, M., ECKER, G. On the relationship between feature selection and classification accuracy. Journal of Machine Learning Research: Workshop and Conference Proceedings of Machine Learning Research. 2008, 4, p. 90-105. ISSN 1938-7228. 